\title{
RECEIVING SETS FOR AIRCRAFT BEACON AND TELEPHONY
}

\author{
By Haraden Pratt and Harry Diamond
}

\begin{abstract}
Special light-weight radio receiving sets of high sensitivity have been designed adapted for the reception on aircraft of signals from radio beacons and ground radiotelephone stations. A statement of the important considerations involved in the aircraft reception of signals from Government-operated beacons and telephone stations along the civil airways in this country, such as frequency range, tuning means, volume control, vacuum tubes, amplifier characteristics, size, weight, and performance specifications, is given.

Design details for three receiving sets of slightly different types, with numerous characteristic and performance curves, are discussed, with a brief discussion of the results of practical flight tests.
\end{abstract}

\section{CONTENTS}

I. Introduction

II. Requirements for beacon and telephone receiving set_........ 544

III. Receiving-set design

1. Design of radio-frequency transformer (interstage) _._. $\quad 549$

2. Effect of capacitive coupling

3. Method of neutralizing

4. Design of antenna transformer

5. Design of regenerative coil_._.

6. Shielding and arrangement of parts_.......... 558

7. Detector _... 559

8. Audio amplifier............ 560

9. Over-all performance $\ldots \ldots$

IV. Conclusion

\section{INTRODUCTION}

The conditions surrounding the use of radio receiving equipment installed on aircraft impose many special considerations of both design and performance. The specifications for aircraft sets, therefore, differ materially from those employed for other purposes.

Such sets at this time are of three types. One type fulfills military requirements where a rather broad band of frequencies must be covered while in flight. Another type is required to receive the signals from beacons and ground radiotelephone stations which the United States Government will supply along the civil airways under the air commerce act. The third type is adapted to the high-frequency (above $1,500 \mathrm{kc}$ ) field. Most of the activities of the past have, in this country, been confined to sets of the first type mentioned. The other two fields are new. 
European radio developments applied to commercial aviation have been under way for several years. Resulting practice has centered around a narrow band of frequencies between 315 and $350 \mathrm{kc}$ for aircraft services. Radiobeacons, particularly those erected in the United States for aiding marine navigation, have adopted adjacent frequencies near $300 \mathrm{kc}$. The 1927 International Radio Conference recognized these established practices and the International Convention allocated the bands 285 to $315 \mathrm{kc}$ for all radiobeacon services and 315 to $350 \mathrm{ke}$ for aircraft communication services, $333 \mathrm{kc}$ being: adopted as an international calling and distress frequency for aircraft. The directive radiobeacons and weather broadcasting services planned for our civil airways will, therefore, be confined to these two bands.

These bands being adjacent and covering a total range of only $65 \mathrm{kc}$ permit of simplifications in receiving-set specifications for this type of service. As part of its research and development work ${ }^{1}$ on directive radio beacons and radiotelephony for aircraft under the air commerce act, the Bureau of Standards has developed such receiving sets, the design elements of which are treated in this paper.

\section{REQUIREMENTS FOR BEACON AND TELEPHONE RE- CEIVING SET}

The dominating requirement in design is that of small weight and physical dimensions. This refers not only to the set, but also to the batteries requisite for its operation. Every design element must be considered in the light of this requirement.

The set must be capable of installation anywhere on the aircraft with simple remote controls when placed at an inaccessible point. The tuning system should, therefore, be of a uni-control type over the entire 285 to $350 \mathrm{kc}$ band for the sake of convenience.

As an aircraft is in very rapid motion, the distance over which signals are traveling is constantly changing. A simple and rugged volume control having a uniform action from zero to maximum signal strength and capable of remote installation from the receiving set is consequently necessary.

Sufficient shielding of the set must be provided to limit interference from the engine ignition system to that induced in the antenna structure.

Rugged construction to withstand the continuous mechanical vibration on aircraft must be provided. Vacuum tubes must be used that do not introduce microphonic noises, which, if present, effectively increase the already prevailing noise level.

${ }_{1}$ Development of radio aids to air navigation, J. H. Dellinger and H. Pratt, Proc. I. R. E., 16, pp. 890920 , July, 1928. 
The set must be capable of operating a beacon course indicating instrument. Its output must efficiently supply a maximum of 10 volts of audio-frequency power into a load impedance of from 4,000 to $7,000 \mathrm{ohms}$, to provide an ample margin of signal strength. The direct current plate supply must be isolated from the output circuit to prevent the observer from receiving shocks when wearing headphones, and to prevent the setting up of a polarization in the course indicator's magnetic system.

The audio amplifiers and output circuit must provide a nearly uniform amplification over a frequency range of 40 to 3,000 cycles. The beacon signals are modulated in the range 40 to 120 cycles, and a voice frequency range from 200 to 3,000 is needed for good intelligibility.

Both the sensitivity and selectivity must be high. High sensitivity is desirable to permit short vertical pole antennas to be employed because they eliminate direction errors and remove the danger of weighted trailing wires. Good selectivity is necessary to enable close spacing of frequency channels.

The choice of vacuum tubes has an important bearing on the total weight and bulk of the equipment. Three types of receiving sets will be described; two of which employ 1-volt and 3-volt tubes, respectively, where the total " $\mathrm{A}$ " battery current is of the order of 0.5 ampere; the third using 5 -voli tubes where the " $\mathrm{A}$ " battery must supply 1.5 amperes. By employing the lower voltage types both the " $A$ " storage battery can be reduced in size and the advantages of vacuum tubes having small physical dimensions secured: The standard low-voltage tubes offered on the market, however, are not sufficiently sturdy for aircraft use, being often mechanically weak and usually causing microphonic noises. Special tubes having these disadvantages to a less degree were employed, but owing to their special nature the third set equipped with the standard 5 -volt tubes was also designed. There is much need for better tubes for aircraft sets, and it is hoped that commercial designs will be improved.

\section{RECEIVING-SET DESIGN}

Figures 1,2 , and 3 show the circuit diagrams of the three receiving sets designed to meet the above requirements, and Figures 4, 5, and 6 are corresponding photographs. Their physical characteristics are tabulated below.

TABLE 1.-Weights and dimensions of receiving sets with associated batteries

\begin{tabular}{r|r|r|r|r|r|}
\hline Receiving set No. & $\begin{array}{c}\text { Weight } \\
\text { of set } \\
\text { (pounds) }\end{array}$ & & Dimensions (inches) & $\begin{array}{c}\text { Weight of } \\
\text { batteries } \\
\text { (pounds) }\end{array}$ \\
\hline 1 & 18 & $\begin{array}{c}91 / 2 \text { by } 71 / 4 \text { by } 161 / 2 \\
21 / 2 \text { by } 9 \text { by } 14\end{array}$ & 19 \\
\hline 3 & 17 & $61 / 4$ by 8 by 13 & 19 \\
\hline
\end{tabular}




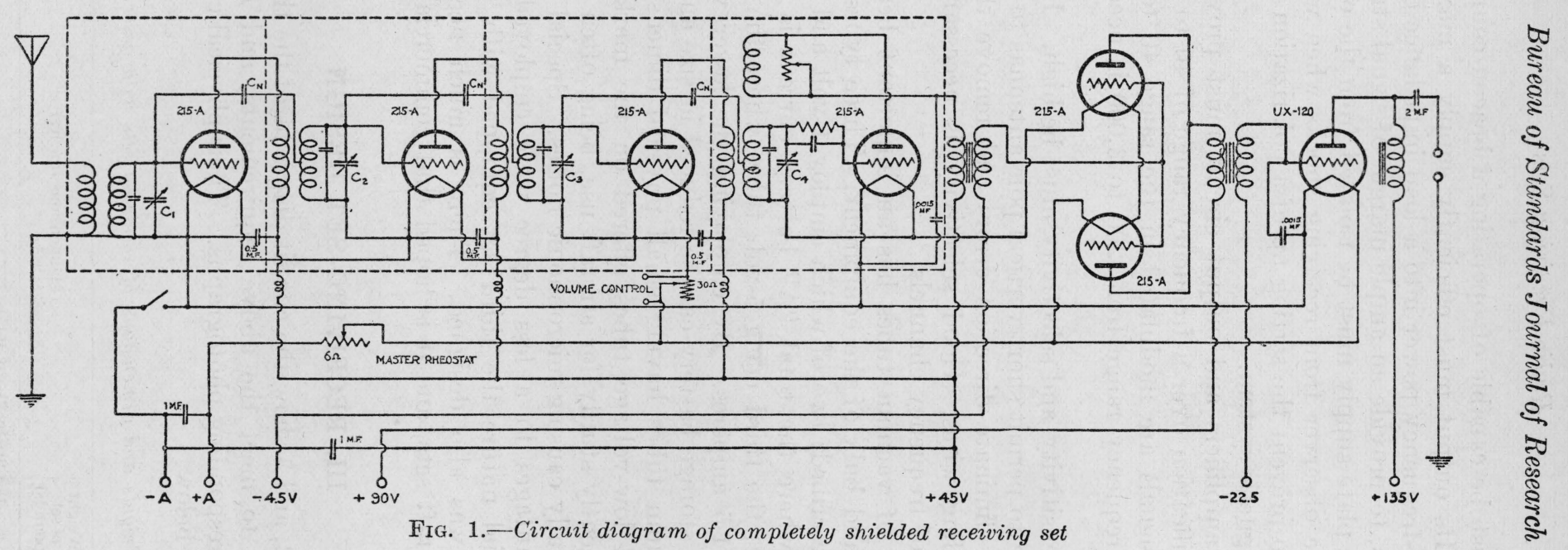




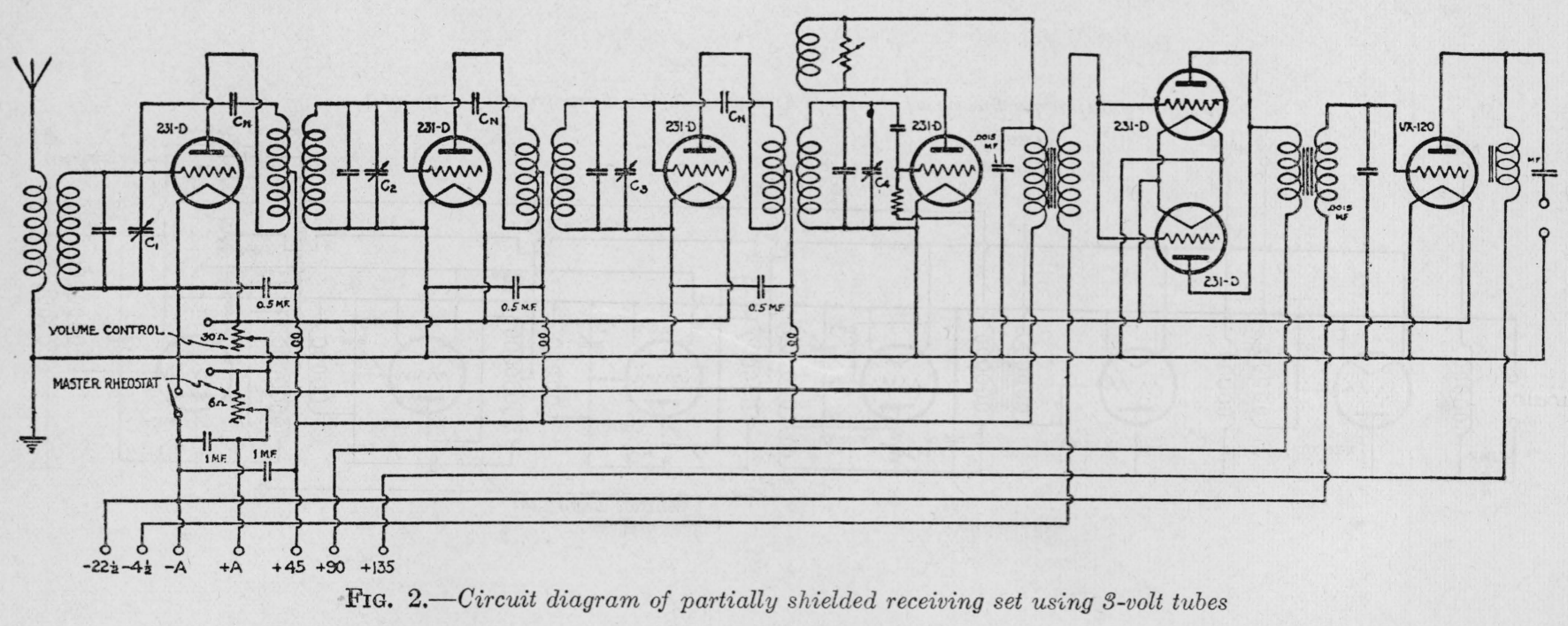




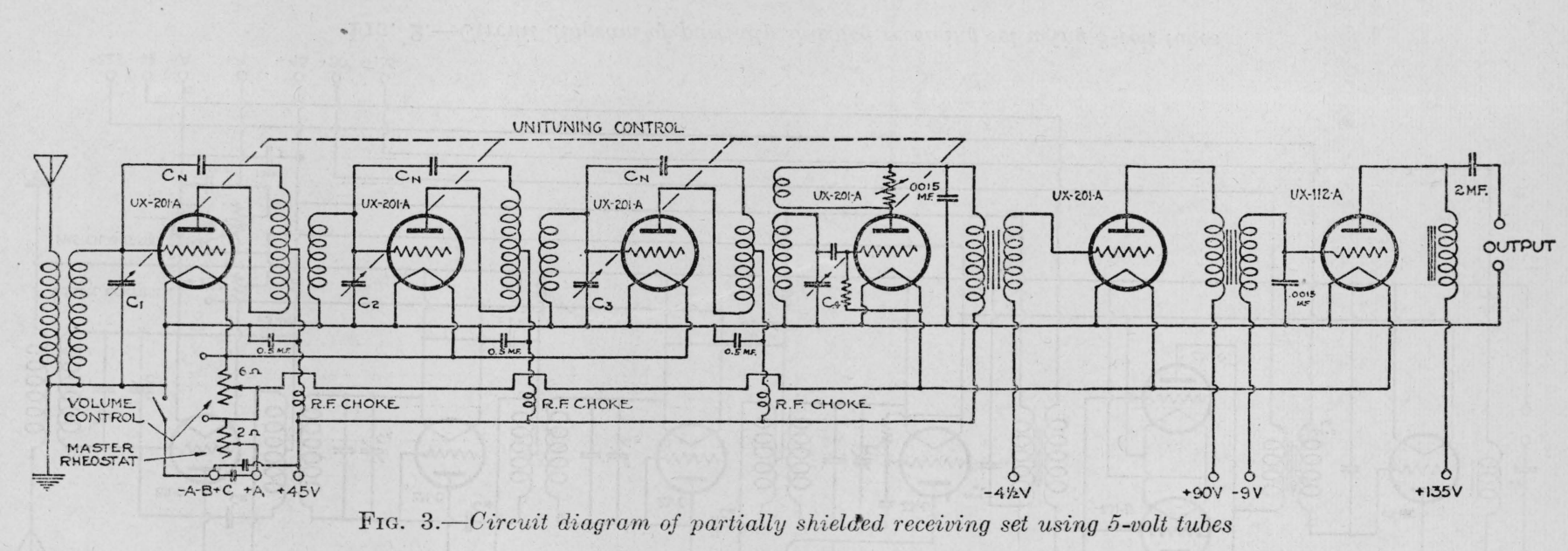


B. S. Journal of Research, RP19

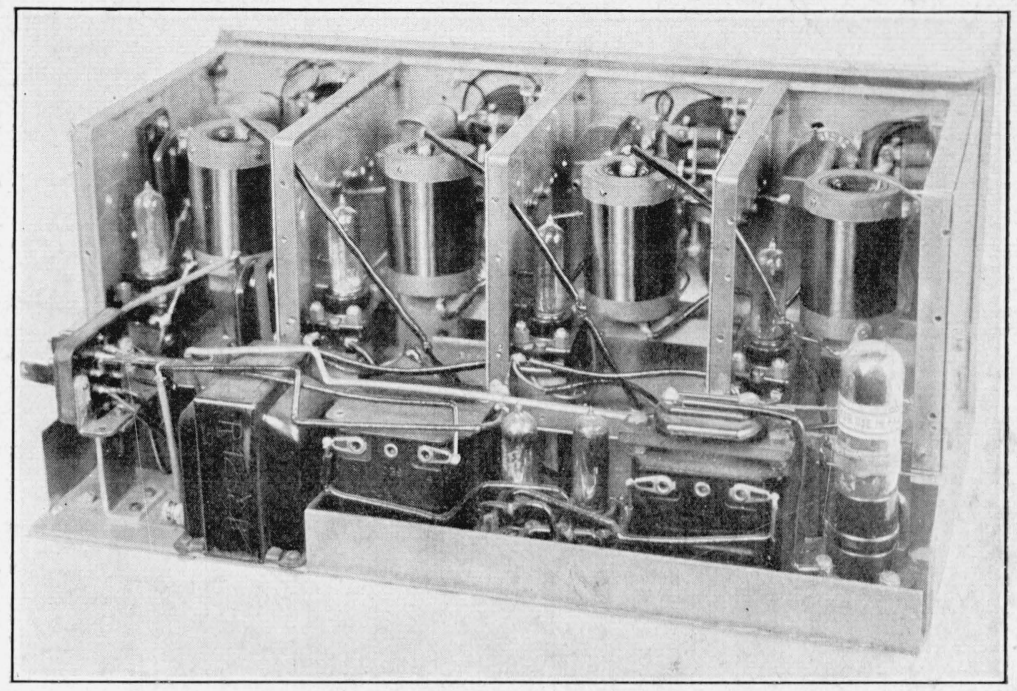

FIG. 4.-Interior of completely shielded receiving set

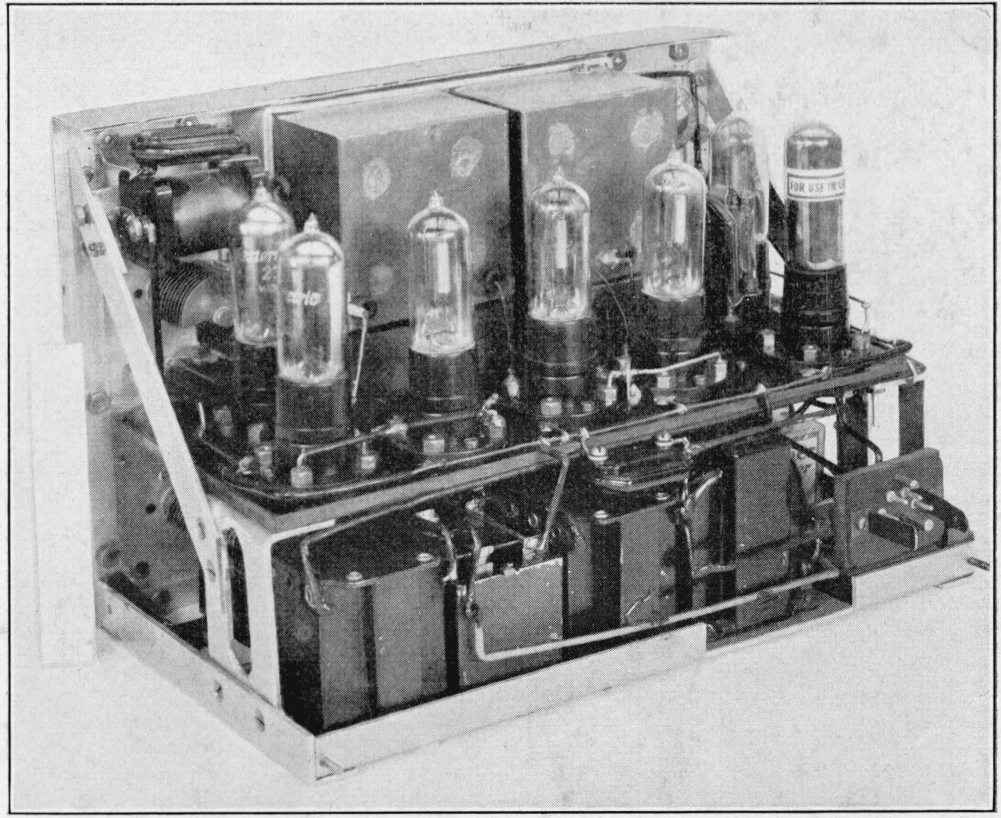

FIG. 5.-Interior of partially shielded receiving set using 3-volt tubes $548-1$ 
B. S. Journal of Research, RP19

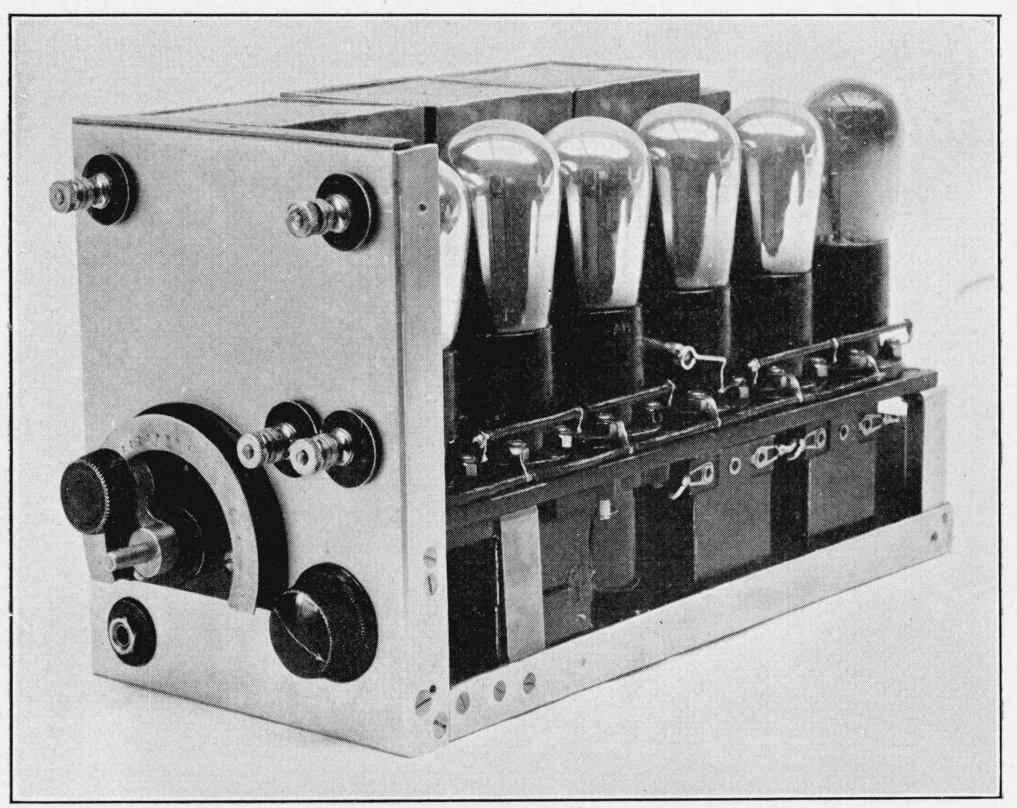

FIG. 6.-Interior of partially shielded receiving set using 5-volt tubes $548-2$ 
Sensitivity, selectivity, and unicontrol features are met by employing three or four tuned radio-frequency amplifier circuits with gang variable air condensers. Some regeneration in the detector circuit is provided. After many trials superheterodyne sets were eliminated from consideration owing to the presence of two tuning positions for each frequency. A few hours of flight would usually bring the aircraft within close range of stations having frequencies such as to create interference by beating with the intermediate frequency or its harmonics. A pilot operating a radio-equipped airplane in bad weather, when the radio services are needed, must devote all his attention to piloting, and the radio set must convey the information it. receives without attention and without interference from other signals or it will lose usefulness and possibly become a hazard.

\section{DESIGIN OF RADIO-FREQUENCY TRANSFORMER (INTERSTAGE)}

Radio-frequency transformer theory has for some time been reduced to mathematical treatment. ${ }^{2}$ A brief consideration of the analysis

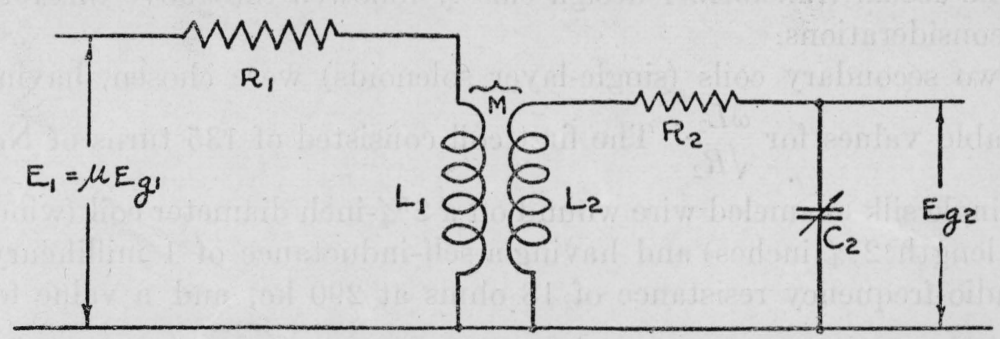

Fig. 7.-Accepted approximate equivalent diagram of a stage of radiofrequency amplification

involved is necessary to a clear understanding of the actual design procedure employed. Figure 7 shows the commonly accepted equivalent circuit corresponding to a stage of radio-frequency amplification employing tuned transformer coupling between stages; $R_{1}$ represents the tube plate resistance plus the radio-frequency resistance of the transformer primary, $L_{1}$ the primary inductance, $M$ the mutual inductance between windings, and $R_{2}, L_{2}$, and $C_{2}$ the constants of the secondary circuit.

In transformer design those values of the three-circuit parameters $X_{1}, X_{2}$, and $M$ which will make the voltage gain per stage a maximum at the desired frequency are of interest. If $X_{2}$ alone is varied (by means of the tuning condenser $C_{2}$ ) the voltage gain is a maximum when

$$
\frac{X_{2}}{X_{1}}=\frac{\omega^{2} M^{2}}{Z_{1}^{2}}
$$

${ }^{2}$ Victor G. Smith, "A mathematical study of radio-frequeney amplification,” Proc. I. R. E., 15, No. 6. pp. 525-536; June, 1927. G. W. Pierce, Electric Waves and Oscillations, MeGraw Hill Book Co. (Inc.). 
If, now, either $X_{1}$ or $M$ is varied, $X_{2}$ being simultaneously varied in order to satisfy the condition expressed by equation (1) for each value of $X_{1}$ (or $M$ ), the voltage gain will reach an optimum value when

$$
\frac{R_{2}}{R_{1}}=\frac{\omega^{2} M^{2}}{Z_{1}^{2}}
$$

Equations (1) and (2) may be combined into the simpler relationship

$$
\omega^{2} M^{2}=Z_{2} Z_{1}
$$

When this relationship is fulfilled the voltage gain $K$ is given by equation (4)

$$
K_{\text {optimum }}=\frac{1}{2} \frac{\mu}{\sqrt{R_{1}}} \frac{\omega L_{2}}{\sqrt{R_{2}}}
$$

and is the maximum amplification that can be obtained with a given tube and coil.

The actual transformer design closely followed the above theoretical considerations.

Two secondary coils (single-layer solenoids) were chosen, having suitable values for $\frac{\omega L_{2}}{\sqrt{R_{2}}}$. The first coil consisted of 135 turns of No. 28 single silk enameled wire wound on a $23 / 4$-inch diameter coil (winding length $23 / 4$ inches) and having a self-inductance of 1 millihenry, a radio-frequency resistance of $18 \mathrm{ohms}$ at $290 \mathrm{kc}$, and a value for $\frac{\omega L_{2}}{\sqrt{R_{2}}}$ at the same frequency equal to 430 . The second coil was of 250 turns of No. 34 enameled wire wound on a $13 / 4$-inch diameter coil (winding length $13 / 4$ inches) and having a self-inductance of 2 millihenries, a radio-frequency resistance of $70 \mathrm{ohms}$ at $290 \mathrm{kc}$, and a value for $\frac{\omega L_{2}}{\sqrt{R_{2}}}$ equal to 435 at this frequency. It should be noted that to cover the necessary frequency range of 285 to $350 \mathrm{kc}$ with a comfortable margin on each side a tuning condenser of $0.00035 \mu \mathrm{f}$ maximum capacity is required with the first coil, and a condenser of $0.00015 \mu$ f maximum capacity with the second coil.

Since $\frac{\omega L_{2}}{\sqrt{R_{2}}}$ is very nearly the same for each coil, the same optimum voltage amplification should be obtained using either coil in conjunction with a given tube. The second coil, however, has the considerable advantage of compactness. Furthermore, since its selectivity is less than that of the first coil (due to its greater resistance), it becomes somewhat more adaptable for use in a unicontrolled multistaged amplifier. 
To determine the optimum value of mutual inductance between windings for each transformer suitable primary forms were chosen and test amplifiers constructed comprising the particular transformer under test together with a given tube. A known voltage of the desired frequency was applied to the input terminals of the test amplifier and the transformer secondary circuit tuned by condenser $C_{2}$ for maximum output voltage (as indicated by a tube voltmeter); these measurements being taken for a series of values of mutual inductance. For each measurement, therefore, equation (1) above is satisfied; while at the particular value of $M$ which yields the opti-

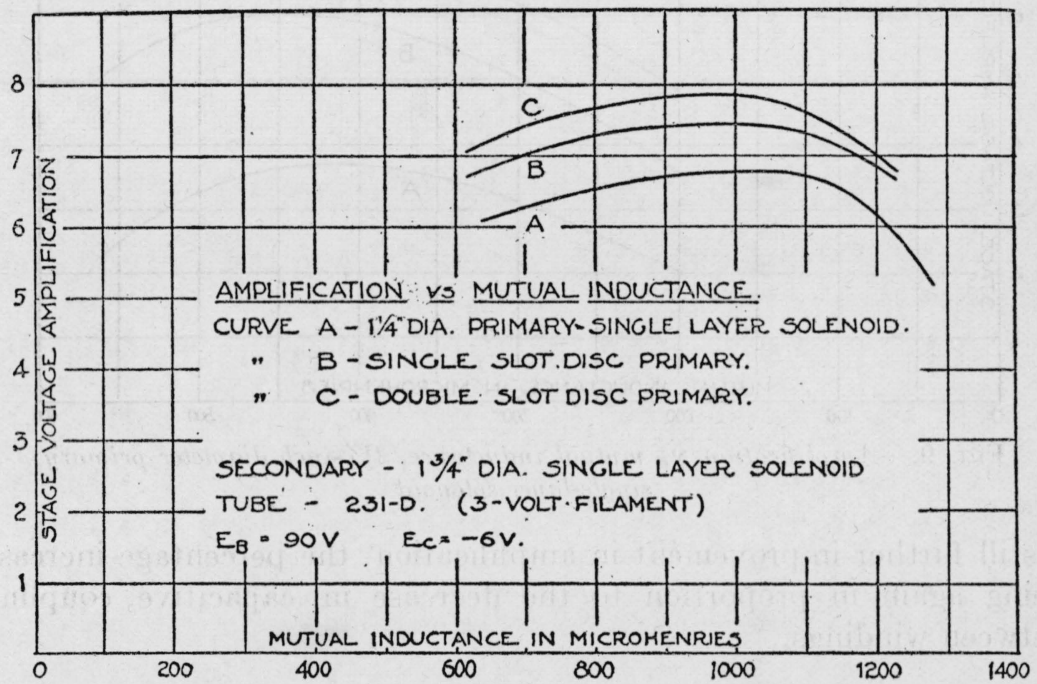

Fig. 8.-Amplification v. mutual inductance, 11/4-inch diameter primary singlelayer solenoid

mum output voltage, equation (2) is, in addition, fulfilled. This is the point of optimum mutual inductance.

Curves $A$ of Figures 8 and 9 show the variation of voltage amplification with mutual inductance for the $13 / 4$ and $23 / 4$ inch diameter transformers, respectively. The amplification obtained with the two transformers is seen to be decidedly different despite the nearly equal values of $\frac{\omega L_{2}}{\sqrt{R_{2}}}$ in each case, and the exactly similar conditions of test; the superiority of the smaller transformer residing in the relatively lower capacitive coupling existing between its windings by virtue of their smaller physical dimensions. That this is true may be seen from a consideration of curves $B$ and $C$ of Figures 8 and 9. Curves $B$ were obtained with the primaries wound in single slotted disks inserted at the low potential ends of the secondaries, thereby reducing the effective capacitive couplings. The resultant increase 
in amplification is greater for the $23 / 4$-inch diameter transformer because of the greater reduction in its capacitive coupling. Distributing the primary windings in two slots in the disk form causes

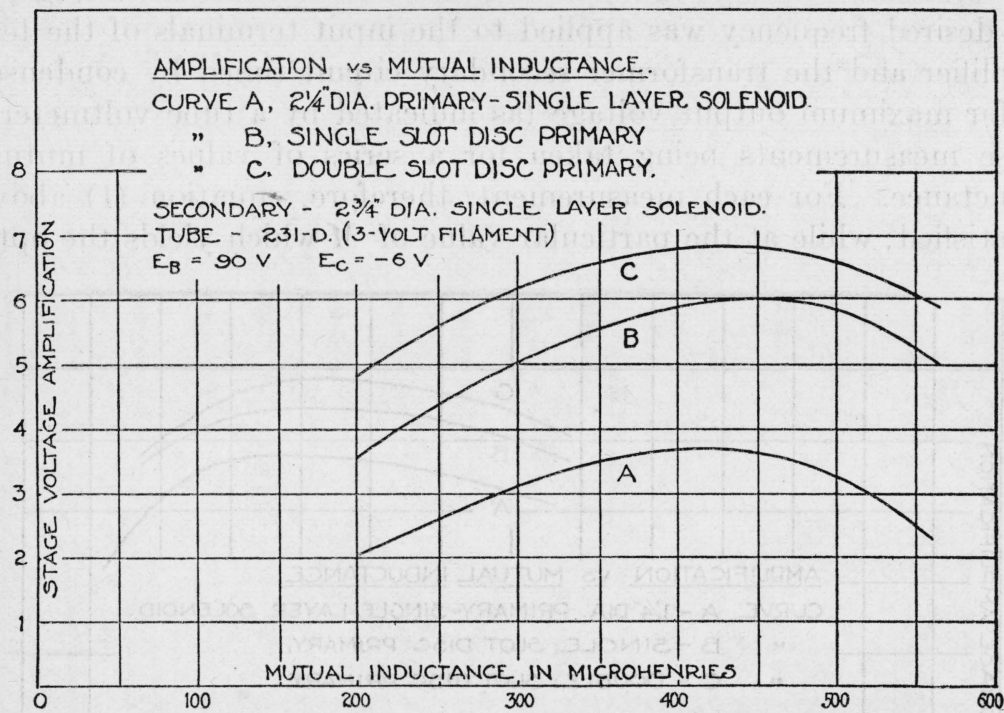

FIG. 9.-Amplification v. mutual inductance, 21/4-inch diameter primary single-layer solenoid

a still further improvement in amplification, the percentage increase being again in proportion to the decrease in capacitive coupling between windings.

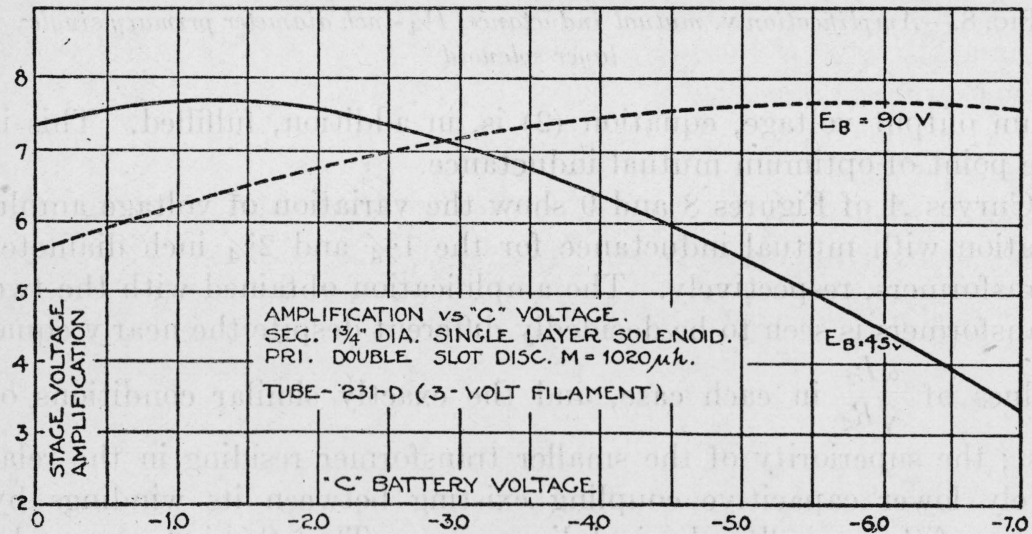

FIG. 10.-Amplification v. " $C$ " voltage

The curves of Figures 8 and 9 were taken for 90 volts on the plate with a grid bias of -6 volts. It was decided to reduce the plate voltage sufficiently to preclude the use of $a$ " $\mathrm{C}$ " battery and thereby to remove the need of filtering in the grid return leads. Figure 10 
shows that the same amplification as in Figures 8 and 9 can be obtained using 45 volts on the plate and $-1 \frac{1}{2}$ volts on the grid. A further reduction of the "C" voltage to zero results in but a small loss in amplification.

Figure 11 gives the amplification-frequency characteristics for the test transformers; the optimum mutual inductance as found from

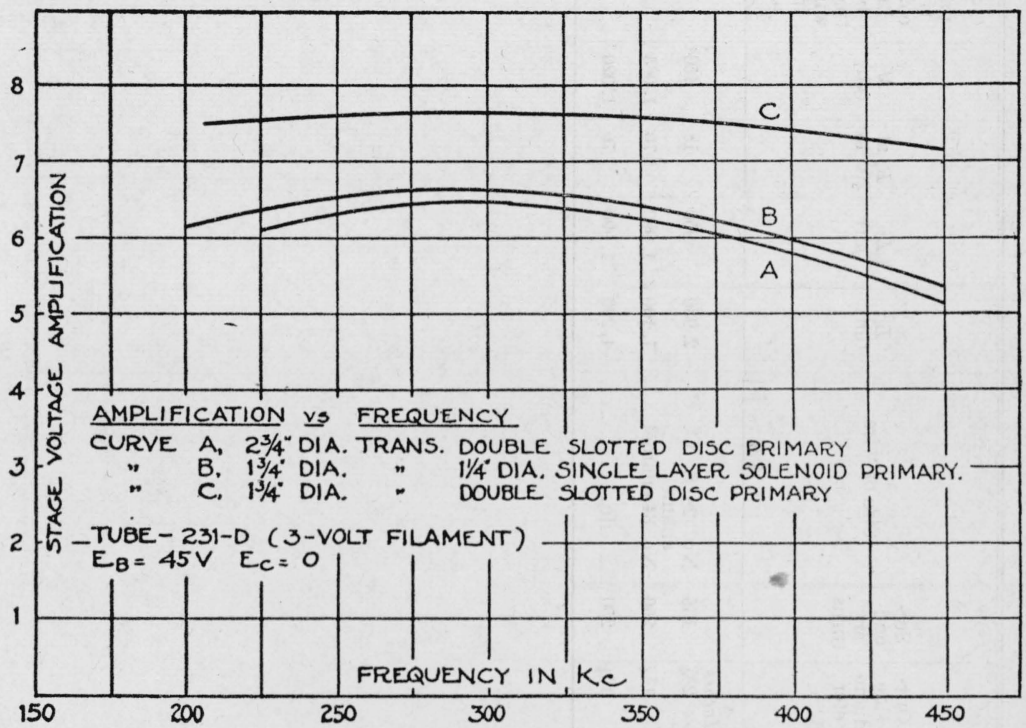

FIG. 11.-Amplification v. frequency

the curves of Figures 8 and 9 being provided in each case. Curve $A$ is for the $23 / 4$-inch diameter transformer with double-slotted disk primary; curve $B$ for the $13 / 4$-inch diameter transformer with single layer primary; and curve $C$ for the $13 / 4$-inch diameter transformer with double-slotted disk primary. All the important constants of these transformers are collected in Table 2. A study of the amplification-frequency characteristics shows that they are highly satisfactory over the desired frequency range (285 to $350 \mathrm{kc}$ ). 
TABLE 2.-Transformer constants

\begin{tabular}{|c|c|c|c|c|c|c|c|c|c|c|c|c|c|c|c|}
\hline $\begin{array}{l}\text { Trans- } \\
\text { former } \\
\text { No. }\end{array}$ & Primary winding & $\begin{array}{c}\text { Outside } \\
\text { diameter }\end{array}$ & $\begin{array}{l}\text { Primary } \\
\text { turns }\end{array}$ & Size of wire & $\begin{array}{c}\text { Secondary } \\
\text { winding }\end{array}$ & $\begin{array}{c}\text { Out- } \\
\text { side } \\
\text { diam- } \\
\text { eter }\end{array}$ & $\begin{array}{l}\text { Sec- } \\
\text { ond- } \\
\text { ary } \\
\text { turns }\end{array}$ & Size of wire & $\begin{array}{c}L_{1} \\
(\mu \mathrm{h})\end{array}$ & $\begin{array}{c}L_{2} \\
(\mu \mathrm{h})\end{array}$ & $\begin{array}{c}R_{2} \text { at } \\
290 \mathrm{kc}\end{array}$ & $\underset{(\mu \mathrm{h})}{M}$ & $\begin{array}{c}\text { Ca- } \\
\text { paci- } \\
\text { tive } \\
\text { coup- } \\
\text { ling } \\
\text { be- } \\
\text { tween } \\
\text { wind- } \\
\text { ing } \\
\mu \mu \mathrm{f}\end{array}$ & $\begin{array}{c}\omega^{2} M^{2} \\
\text { at } 290 \mathrm{kc}\end{array}$ & $\begin{array}{l}Z_{1} Z_{2} \\
\text { at } 290 \mathrm{kc} \text {, } \\
\text { approxi- } \\
\text { mately }\end{array}$ \\
\hline 1 & Double-slot disk & $\begin{array}{r}\text { Inches } \\
25 / 8\end{array}$ & 135 & No. 38 S. C. C.- & Single-layer & $\begin{array}{r}\text { Inches } \\
23 / 4\end{array}$ & 135 & No. 28 s. C. C. & 2,930 & 950 & 18 & 450 & 18 & $0.67 \times 10^{6}$ & $0.34 \times 10^{6}$ \\
\hline 2 & Single-layer sole- & $11 / 4$ & 250 & No. 34 enamel... & ..... do do...... & $13 / 4$ & 250 & No. 34 enamel & 1,100 & 1,990 & 70 & 1,065 & 18 & 3. $77 \times 10^{6}$ & 1. $27 \times 10^{6}$ \\
\hline 3 & Double-slot disk.- & $11 / 2$ & 250 & No. 38 S. C. C.. & ..... do ... & $13 / 4$ & 250 & .... do & 4,290 & 1,990 & 70 & 1,020 & 6 & $3.44 \times 10^{6}$ & 1. $37 \times 10^{6}$ \\
\hline
\end{tabular}


In Figure 12 are shown the resonance curves of the above three transformers, used in conjunction with a 3 -volt tube. Curves $A$, $B$, and $C$ correspond to the transformers of curves $A, B$, and $C$, respectively, of Figure 11. It is interesting to note the mutual inductance effect upon the selectivity. Figure 13 indicates how the selectivity varies for four values of $M$, using the $13 / 4$-inch diameter transformer with double-slotted disk primary.

\section{EFFECT OF CAPACITIVE COUPLING}

It was shown above that the presence of capacitive coupling between windings adversely affects the efficient operation of a trans-

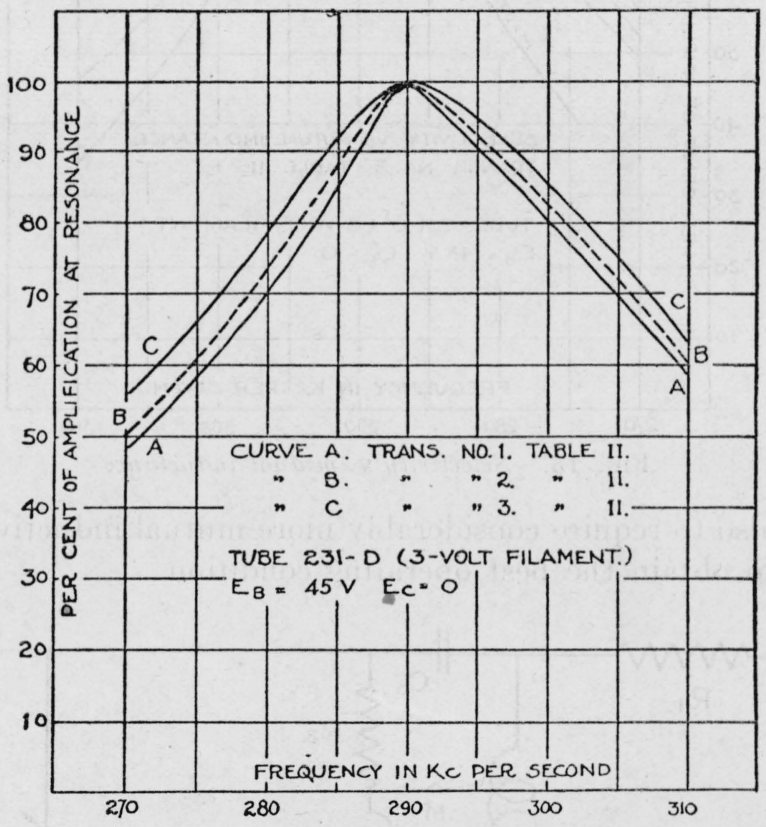

FIG. 12.-Amplification v. frequency

former. When capacitive coupling exists, the approximate equivalent circuit diagram becomes as shown in Figure 14 rather than that of Figure 7. The conditions for optimum voltage gain and the actual magnitude of this optimum gain as found from a solution of this circuit are also different.

A close agreement between experimental results and the theoretical equations based on the circuit of Figure 7 can not, therefore, be expected unless the effect of capacitive coupling is minimized. As computed from equation (3) the optimum mutual inductance for transformer Nos. 1, 2, and 3 of Table 2 should be 315, 615, and $615 \mu \mathrm{h}$, respectively. Actually, the values obtained in the laboratory are $450,1,065$, and $1,020 \mu \mathrm{h}$, respectively. 
The effect of capacitive coupling between transformer windings is thus not only to reduce the magnitude of the optimum voltage

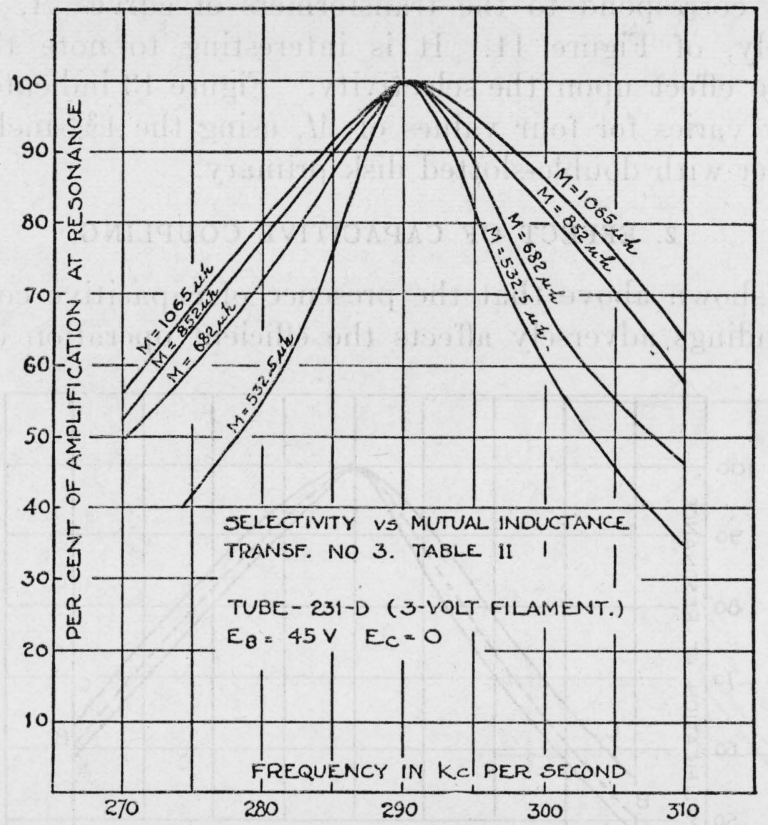

FIG. 13.-Selectivity v. mutual inductance

gain but also to require considerably more mutual inductive coupling in order to obtain the best operating condition.

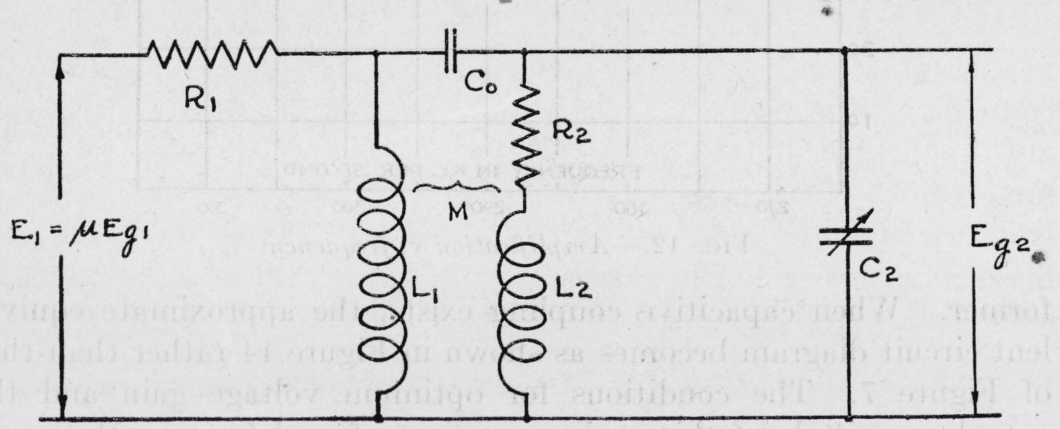

FIG. 14.-Closer approximate equivalent diagram of a stage of radiofrequency amplification

\section{METHOD OF NEUTRALIZING}

The system of tube grid-plate capacity neutralization adopted depends considerably upon the type of transformer employed. The neutralizing schemes in common use are essentially bridge circuits in which two coils, the grid-plate tube capacity, and a neutralizing con- 
denser constitute the four bridge arms. The bridge maintains a balanced adjustment for all operating frequencies, provided the two coil arms are tightly coupled. When the coupling between the two coils is small a leakage inductance is introduced into one of the bridge arms, thus making the balance dependent upon the frequency.

With several neutralizing systems the primary and secondary windings of the transformer may be used as the two coil arms, provided there is sufficient coupling between them. In the case of the $13 / 4$-inch diameter transformer with single-layer primary, a coupling coefficient of the order of 70 per cent obtains. The system employed can, therefore, be that indicated in the circuit diagram of Figure 1.

In the case of the $13 / 4$-inch diameter transformer with disk primary (used in the receiving set of fig. 2), however, the coupling coefficient between windings was about 35 per cent. The use of an auxiliary coil coupled either to the primary or secondary winding is therefore necessary. A simple solution consisted in placing the auxiliary coil

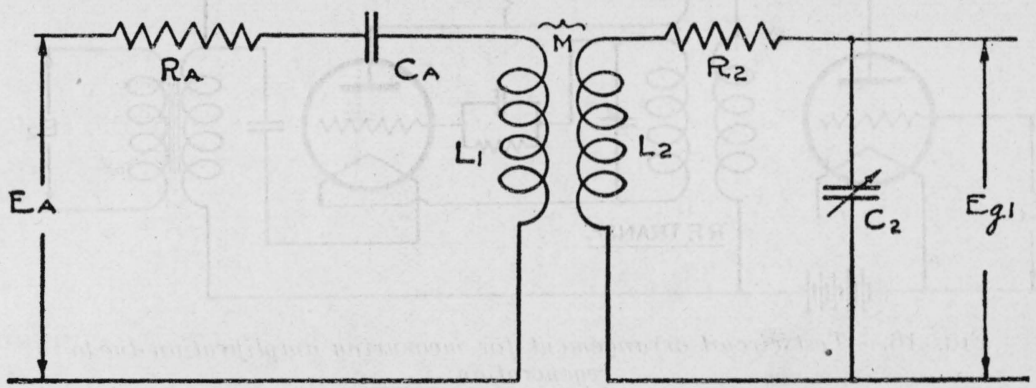

FIG. 15.-A pproximate equivalent diagram of antenna tuning system

in a third slot in the primary disk form thus obtaining nearly unity coupling to the primary. An alternative method, due to Miller, is also applicable in this case. In this method the four bridge arms are made up of the tube grid-plate capacity, a neutralizing condenser, and two auxiliary condensers, one of which may be the tube gridfilament capacity. The closeness of coupling between primary and secondary windings is here obviously immaterial.

\section{DESIGN OF ANTENNA TRANSFORMER}

No mention has as yet been made concerning the design of the antenna coupling transformer. The theory and procedure of design is essentially the same as for interstage transformers. The equivalent circuit is that of Figure 15, where $C_{\mathrm{A}}$ is the antenna capacity and $R_{\mathrm{A}}$ the equivalent antenna resistance. Receiving set sensitivity of such order was desired as to make possible the use of a rigid antenna of about 10 feet in length, with the airplane itself as a counterpoise. The capacity of such a system is of the order of 25 to 50 
$\mu \mu f$. Using these values, the same transformer as used for interstage coupling was found highly satisfactory.

\section{DESIGN OF REGENERATIVE COIL}

To obtain the order of amplification desired, it was decided to use three stages of radio-frequency amplification with regeneration on the detector. The circuit arrangement of Figure 16 was used in the design of the regenerative coil. A known modulated voltage $E_{1}$ (of the desired radio-frequency) was applied to the input circuit and the voltage $E_{2}$ measured first without regeneration and then with regeneration. The ratio of the second to the first value of $E_{2}$ is the amplification due to regeneration. These measurements were taken for a series of values of regenerative coil turns, adjusting the shunting resistance $R$ to just below oscillation at each point (where necessary).

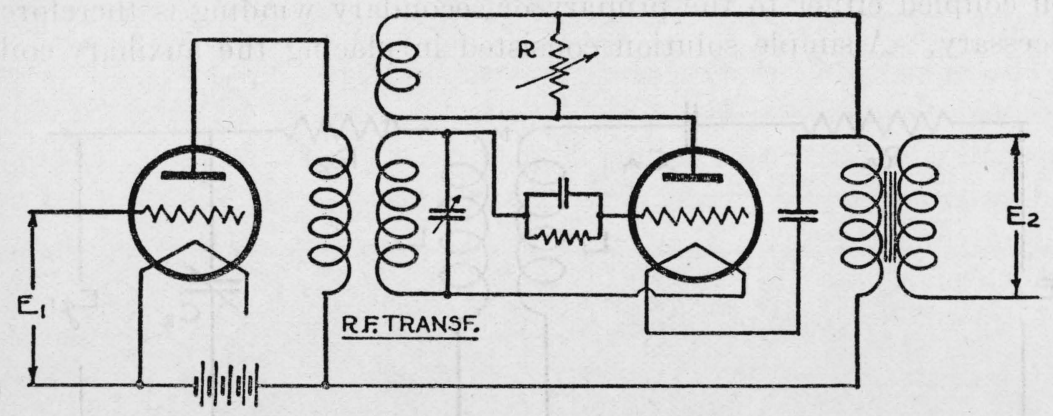

FIG. 16.-Test circuit arrangement for measuring amplification due to regeneration

For the particular transformer considered, it was found that the best value of turns was approximately 40 per cent of the number of turns in the secondary winding.

\section{SHIELDING AND ARRANGEMENT OF PARTS}

Both complete and partial shielding methods were employed in the tuned amplifier stages. Reference to Figures 4, 5, and 6 will indicate the shielding arrangements. Completely shielding the stages as in Figure 4 was found to be difficult owing to the involved mechanical assembly. Aluminum was selected to reduce weight, but resulted in objectionable eddy-current losses. Partial shielding using copper containers housing the radio-frequency transformers, with proper care taken to make all high potential leads as short as possible, resulted satisfactorily. This latter method was applied as shown in Figures 5 and 6.

The copper containers maintain an effective clearance of seveneighths inch around the coil windings, and are of square cross section. The coil inductances are decreased by about 20 per cent without any material increase in resistance. 
To confine the radio-frequency currents as far as possible to the shielded portions of the set, battery leads were filtered where necessary. The selection of a low-plate voltage served not only to reduce the demand on the " $\mathrm{B}$ " battery, but to permit the radio-frequency stage grid returns to be connected directly to the negative filament terminals, eliminating a common "C" battery impedance. All other precautions in arrangements and wiring used in good design practice were observed. A multiple conductor battery cable, equipped with a detachable plug connector, was provided to allow a rapid change of sets to be made when in practical operation.

A small separate panel containing a combination " $\mathrm{A}$ " and "B" battery voltmeter, filament switch, head telephone jack, and volume control was provided for mounting near the pilot, preferably on the instrument board. The volume control consists of a rheostat connected in the radio-frequency amplifier tube filament supply circuit.

The unicontrol tuning feature makes it possible for the operator to tune to any station frequency within the two bands. In this case an antenna coupling arrangement is needed which makes the setting of the antenna tuning condenser at a given frequency independent of the antenna length. This is taken care of by an antenna trimming condenser.

Adjustable stops to allow the unicontrol handle to be rapidly turned from one predetermined frequency in the 285 to $315 \mathrm{kc}$ band to one in the 315 to $350 \mathrm{kc}$ band were provided.

An alternative tuning arrangement was incorporated in one of the receiving sets built, applicable for the case where only one beacon and one telephone frequency would be encountered on any one airplane run. Two sets of condensers connected in parallel were used in each tuned amplifier stage. Normally with both condensers in circuit the tuning adjustment is made for the beacon station frequency. When a switch is closed by the operator four small automatic relays respond, removing one condenser from each circuit, leaving the set tuned to the telephone station frequency which is in the higher band.

\section{DETECTOR}

In general, grid rectification has been found considerably more sensitive than plate detection, and was, therefore, used. Laboratory measurements gave 3 megohms as the optimum value for the grid leak and $0.00035 \mu \mathrm{f}$ as the best value of blocking condenser at the frequencies used. These values are not at all critical.

Sensitivity, however, is not always the deciding factor in the choice of the type of detection to be employed. When used in an airplane not excellently shielded, the ignition interference picked up by the antenna structure may be sufficient to block the detector, even though 
the incoming signal is small. By using plate detection a considerably greater interference would be necessary for blocking the detector. Since the present form of course indicator suggested for the beacon signals is practically immune to interference, it will operate satisfactorily so long as the tubes employed are not blocked. It should be noted, however, that plate detection precludes the use of a transformer in the detector output due to the large tube plate resistance with this form of detection.

\section{AUDIO AMPLIFIER}

The low amplification factor of the 3 -volt tubes used in the first two models (figs. 1 and 2 ) necessitated the use of transformer coupling to provide a degree of audio amplification sufficient to supply the desired voltage to the power tube without overloading the detector.

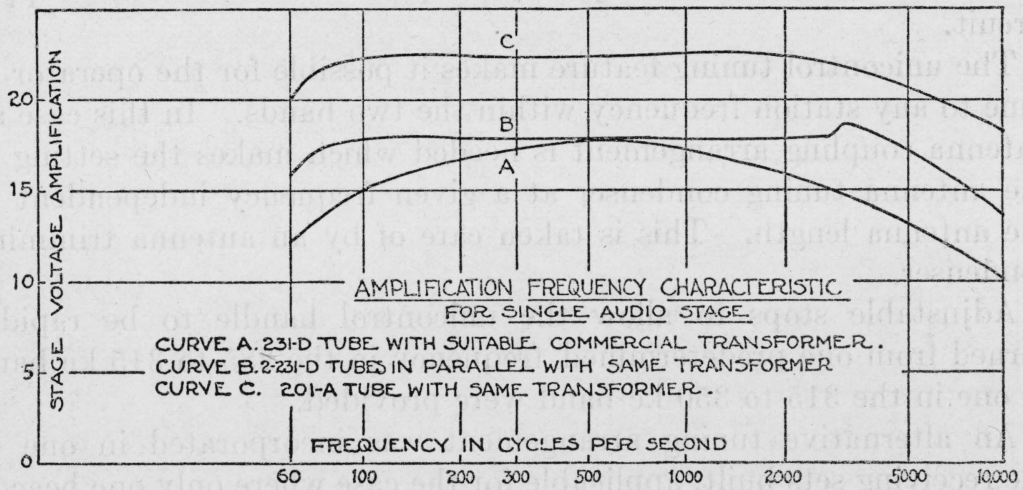

FIG. 17.-Amplification-frequency characteristic for single audio stage

Due to the relatively high plate resistance of these tubes, however, the low frequency pitches are not amplified in the same magnitude as those of higher frequencies. This is indicated in curve $A$ of Figure 17 , which represents the amplification-frequency characteristics for a 3-volt tube used together with a commercial transformer. A large number of commercial transformers were tested, the one finally adopted being chosen for its lightness as well as its electrical characteristics. A much more uniform gain over the desired frequency range is obtained by using two tubes in parallel in the first audio stage in order to reduce the net plate resistance. The amplification-frequency characteristic for this condition is given by curve $B$ of Figure 14 . This arrangement was, therefore, used in both the 3 -volt receiving sets. Curve $C$ shows that when 5 -volt tubes are used a satisfactory characteristic is obtained with one tube in the first audio stage.

Using 5 -volt tubes a resistance-coupled audio amplifier immediately suggests itself. The third model (fig. 3) employing 5-volt tubes uses transformer coupling, however, chiefly for the sake of flexibility. In 
this set it is feasible to use either 3 or 5 volt tubes throughout, requiring only a change in the size of the filament control rheostats. The operator can, therefore, decide as to whether the cost of tubes or weight of battery is the chief consideration.

Quite fortunately, the impedance of the visual course indicator is suitable for use with any of the power tubes available. The choice of the power tube is therefore controlled by the filament voltage and plate battery consumption. A filter arrangement consisting of a choke and condenser is used in the output circuit for reasons previously mentioned. In the case of a resistance-couplied amplifier this filter circuit would also tend to prevent low-frequency oscillation.

\section{OVER-ALL PERFORMANCE}

The performance of a receiving set may be indicated by means of three graphs; the first showing the variation of sensitivity with carrier frequency; the second showing the degree of its selectivity at several carrier frequencies; and the third giving a picture of its fidelity or response to audio frequencies which modulate the carrier to which it

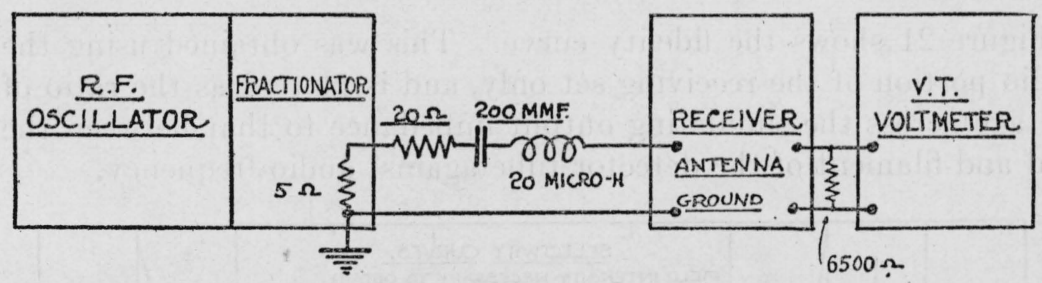

FIG. 18.-Test circuit arrangement for measuring receiving set performance

is tuned. The conditions under which these tests should be taken have been worked out by the Standardization Committee of the Institute of Radio Engineers for broadcast sets. Those conditions apply here also in large measure, but some departures were found desirable in order to more closely approximate actual use.

The sensitivity curve (fig. 19) was obtained with the circuit arrangement of Figure 18. For convenience, 100 per cent modulation at an audio-frequency of 60 cycles was employed. This more nearly approximates actual conditions as low modulating frequencies of the order of 60 cycles are used in the beacon, and the modulation is constant and as near 100 per cent as can be obtained. The curve shows the relationship between the radio field intensity in microvolts per meter necessary to obtain 6 volts across the $6,500-0 \mathrm{hm}$ load and the carrier frequency to which the receiving set is tuned.

The value of 6 volts was chosen, since this is the maximum voltage needed across the present type of course indicator.

Figure 20 shows the selectivity curves for the set when tuned to 290 and $330 \mathrm{ke}$. These are, respectively, the approximate beacon 
and phone frequencies. These curves represent the field intensity in microvolts per meter to give 6 volts across the simulating impedance referred to the carrier frequency.

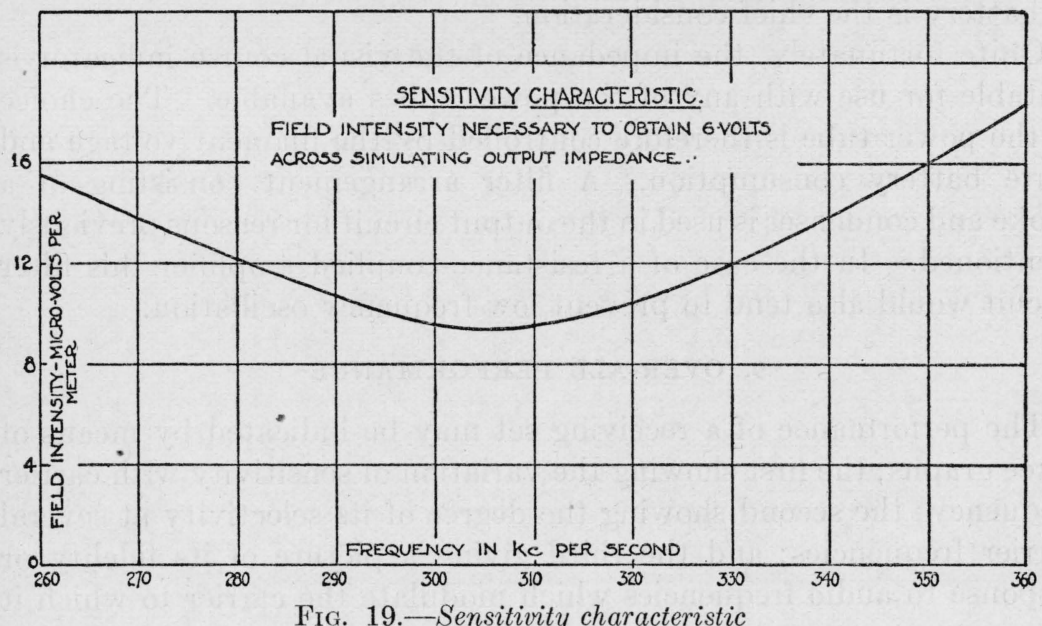

Figure 21 shows the fidelity curve. This was obtained using the audio portion of the receiving set only, and is plotted as the ratio of voltage across the simulating output impedance to that between the grid and filament of the detector tube against audio-frequency.

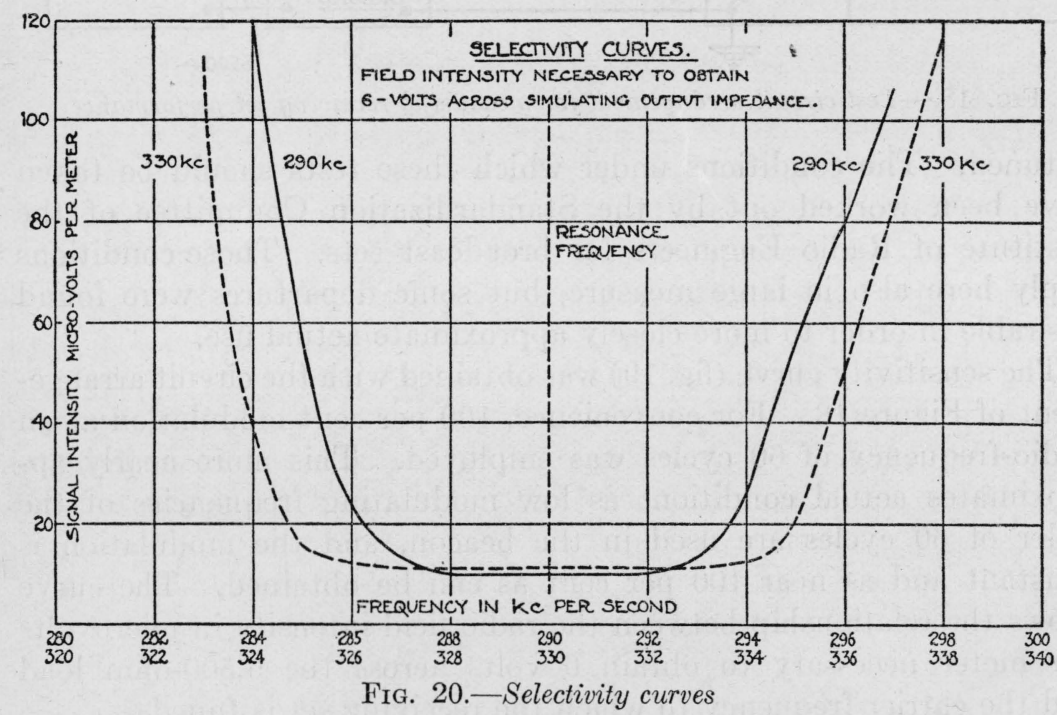

Twenty volts across the simulating output impedance was obtained before tube overloading occurred.

It should be noted that the curves of Figures 19, 20, and 21 were obtained with one of the 3 -volt sets. When 5 -volt tubes are used, 
measurements indicate that the performance of the radio-frequency amplifier is but slightly altered. The voltage gain in the audio amplifier will, however, be considerably increased due to the greater tube amplification factors.

\section{CONCLUSION}

These sets were developed concurrently with the double modulation type of directive radio beacon, the reed type of visual indicator for aircraft, and the airplane vertical pole antenna, all of which are parts of the bureau's research program on aids to air navigation. The development of these receiving sets was found essential because of the special receiving requirements on airplanes peculiar to these air

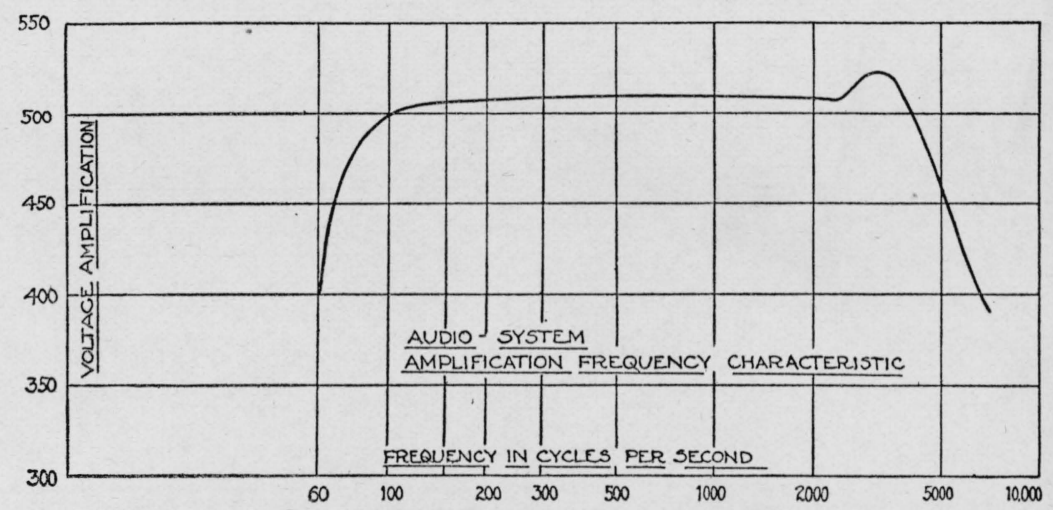

FIG. 21.-A udio system amplification-frequency characteristic

navigation aids. Without receiving sets of high sensitivity, the elimination of the dangerous trailing wire antenna, and the reduction of night beacon course shift errors obtained with the short vertical antenna, would not be possible.

The second set described was extensively used in flight tests for a period of six months. Satisfactory daytime beacon signals were received on an airplane at a distance of 100 miles with an antenna 10 feet high, the engine ignition system being adequately shielded.

The writers wish to acknowledge the assistance of L. L. Hughes and D. O. Lybrand in constructing these sets, including several preliminary models.

Washington, June 19, 1928. 
